\title{
Relation between Intelligence Quotient (IQ) and Velopharyngeal Dysfunction in Repaired Cleft Palate Patient
}

\author{
AHMED ABDELKARIM, M.B.B.Ch.*; TAREK RAIEF, M.D.*; EMAD K. ABDEL HALEEM, M.D.** and \\ HASSAN S. YOUSSEF, M.D.* \\ The Departments of Plastic Surgery* and Phoniatrics, ENT**, Assiut University Hospital, Assiut, Egypt
}

\begin{abstract}
Background: In children born with cleft (lip and) palate resonance and articulation disorders are often observed as a result of structural deviations of the sound production mechanism. Even after palatal closure, compensatory articulation and resonance disturbance may persist, despite advances in surgical treatment of congenital orofacial clefts [1].

Material \& Methods: This is a cross-sectional study that was conducted upon 70 patients with repaired cleft palate of different grades in Plastic Surgery Department Assiut University Hospital. Data was collected from May 2016 to December 2018.

Results: The study enrolled 70 children with cleft palate and underwent palatoplasty; out of them 18 (25.7\%) patients developed velopharyngeal dysfunction (VPI). $66 \%$ of patient with velopharyngeal insufficiency has below average IQ.
\end{abstract}

Key Words: Cleft palate - Velopharyngeal dysfunction - IQ.

\section{INTRODUCTION}

The necessity of expanding reliable knowledge regarding speech development and surgical methods is essential in providing care for children born with cleft lip and palate [2].

Two important factors could affect the outcome of cleft palate repair; the timing and the technique of palatoplasty. It has long been recognized that the best speech results are obtained when the palate is repaired before the development of meaningful, connected speech which also affected by the cognitive development of the patient [3].

Cognitive dysfunction in children with clefts of the lip and palate has been documented for decades. Studies evaluating this issue reported that children with non-syndromic clefts had lower IQs [4].

It is important to recognize the relation between the cognitive ability of the patient and its direct relation with speech which will have a direct effect on treatment of velopharyngeal dysfunction.

\section{PATIENTS AND METHODS}

This study was conducted upon 70 patient who had cleft palate repair of different grades in Plastic Surgery Department Assiut University Hospital. It is a cross-sectional study data collected between May 2016 to December 2018. We exclude patients with other medical, mental diseases or syndromic cases. Sample size was calculated using EPI info 2000 computer program taking percentage of occurrence $40 \%$, worst acceptable result $50 \%$ and confidence percentage $90 \%$.

After collecting the standard history data, developmental history and age of last palatoplasty. we started with elementary diagnostic procedures including auditory perceptual assessment. Videonasopharyngoscopy and high-fidelity voice recording as clinical diagnostic aid was done.

IQ test according Stanford-Binet Intelligence scale IV [5]. Also CT scanning of the velopharyngeal port, aerodynamics, and acoustic analysis was done for some cases [6].

Treatment plan was chosen after considering velopharyngeal closure type (coronal or sagittal or circular) and velopharyngeal movement (palatal movement and lateral pharyngeal wall movement).

The patients with adequate movement and small velopharyngeal gap were candidate for speech therapy (12 cases) and for the patients with large or moderate velopharyngeal gap (6 cases).

We divided the patients according to the velopharyngeal valve movements and velopharyngeal closure into; patients with adequate lateral wall movement and poor palatal movement (coronal closure) who were candidate for pharyngeal flap (4 cases), patients with adequate palatal movement and poor lateral wall movement (sagittal closure) 
were candidate for pharyngeal sphincteroplasty (one case), patients with poor palatal and lateral wall movement (circular closure) are candidate for pharyngeal sphincteroplasty (one case).

Post-operative evaluation was done one month after surgery to determine success and effectiveness of surgery on patient's speech.

Data was collected and analyzed using SPSS (Statistical Package for the Social Science, Version 20, IBM, and Armonk, New York).

Chi-square test was used to compare the nominal data of different groups in the study while student $t$-test and Mann-Whitney test was used in case of not-normally distributed data.

\section{RESULTS}

Table (1) shows the baseline characteristics of studied group. Mean age of all studied children was $5.54 \pm 4.11$ years with range between 2.5 and 21 years. Majority (71.4\%) of studied patients had cleft lip while ear, neonatal and prenatal problems presented in $6(8.6 \%), 6(8.6 \%)$ and $2(2.9 \%)$ patients respectively.

Fifty $(71.4 \%)$ patients had grade IV cleft palate, $8(11.4 \%)$ had grade III, $10(14.3 \%)$ had grade II while only two patients had submucosal; cleft palate. The age last palatoplasty ranged between 1 and 6 years with mean age was $2.12 \pm 1.24$ years. Median number of palatoplasty was one year with range between one and there years.

Table (1): Baseline characteristics of studied group.

\begin{tabular}{ll}
\hline & $\mathrm{N}=70$ \\
\hline Age (years) & $5.54 \pm 4.11$ \\
Range & $2.5-21$ \\
History of: & \\
$\quad$ Prenatal problem & $2(2.9 \%)$ \\
Neonatal problem & $6(8.6 \%)$ \\
Ear problem & $6(8.6 \%)$ \\
Cleft lip & $50(71.4 \%)$ \\
Grade of cleft palate: & \\
Submucosal & $2(2.9 \%)$ \\
Grade II & $10(14.3 \%)$ \\
Grade III & $8(11.4 \%)$ \\
Grade IV & $50(71.4 \%)$ \\
Age of last palatoplasty (years) & $2.12 \pm 1.24$ \\
Range & $1-6$ \\
Number of palatoplasty & $1(1-3)$
\end{tabular}

- Data was expressed in form mean (SD), median (range) and frequency (percentage).
Auditory perpetual assessment is shown at (Table 2). Majority $(88.9 \%$ ) of patients with VPI had open nasality and $2(11.1 \%)$ patients had mixed open and closed nasality. As regarding the degree of nasality in those patients with VPI; slight, mild, moderate and severe nasality presented in 8 (44.4\%), 4 (22.2\%), $2(11.2 \%)$ and $4(22.2 \%)$ patients respectively.

Majority (55.6\%) of patients with VPI had moderate consonant imprecision while $46(88.5 \%)$ patients of those without VPI had normal consonant precision. Only $5(11.5 \%)$ patients of those without VPI had glottal compensatory mechanism. Glottal, pharyngeal and mixed compensatory articulation presented in $6(33.3 \%), 2(11.1 \%)$ and $10(55.6 \%)$ patients respectively of those with VPI.

It was noticed that $16(88.9 \%)$ of those with VPI had audible nasal air escape and also, 8 (44.4\%) patients had facial grimace. As regarding overall unintelligillity; 8 (15.4\%) patients of those without VPI had slight overall unintelligillity while 8 (44.4\%), 4 (22.2\%), $2(11.1 \%)$ and $4(22.2 \%)$ patients with VPI had slight, mild, moderate and severe overall unintelligillity. All parameters of auditory perceptual assessment had significant differences between both groups of patients.

Table (2): Auditory perceptual assessment.

\begin{tabular}{|c|c|c|c|}
\hline & $\begin{array}{l}\text { Without VPI } \\
\quad(\mathrm{n}=52)\end{array}$ & $\begin{array}{l}\text { With VPI } \\
(\mathrm{n}=18)\end{array}$ & $\begin{array}{c}p- \\
\text { value }\end{array}$ \\
\hline $\begin{array}{l}\text { Nasality type: } \\
\text { None } \\
\text { Open } \\
\text { Mixed }\end{array}$ & $\begin{array}{l}52(100 \%) \\
0 \\
0\end{array}$ & $\begin{array}{l}0 \\
16(88.9 \%) \\
2 \quad(11.1 \%)\end{array}$ & $<0.001$ \\
\hline $\begin{array}{l}\text { Nasality degree: } \\
\text { Normal } \\
\text { Slight } \\
\text { Mild } \\
\text { Moderate } \\
\text { Severe }\end{array}$ & $\begin{array}{l}52(100 \%) \\
0 \\
0 \\
0 \\
0\end{array}$ & $\begin{array}{l}0 \\
8(44.4 \%) \\
4(22.2 \%) \\
2(11.2 \%) \\
4(22.2 \%)\end{array}$ & $<0.001$ \\
\hline $\begin{array}{l}\text { Consonant imprecision: } \\
\text { Normal } \\
\text { Slight } \\
\text { Mild } \\
\text { Moderate }\end{array}$ & $\begin{array}{ll}46 & (88.5 \%) \\
4 & (7.7 \%) \\
2 & (3.8 \%) \\
0 & \end{array}$ & $\begin{array}{l}2(11.1 \%) \\
6(33.3 \%) \\
0 \\
10(55.6 \%)\end{array}$ & $<0.001$ \\
\hline $\begin{array}{l}\text { Compensatory } \\
\text { articulation: } \\
\text { No } \\
\text { Glottal } \\
\text { Pharyngeal } \\
\text { Mixed }\end{array}$ & $\begin{array}{ll}46 & (88.5 \%) \\
6 & (11.5 \%) \\
0 & \\
0 & \end{array}$ & $\begin{array}{lr}0 & \\
6 & (33.3 \%) \\
2 & (11.1 \%) \\
10 & (55.6 \%)\end{array}$ & $<0.001$ \\
\hline Audible nasal air escape & 0 & $16(88.9 \%)$ & $<0.001$ \\
\hline Facial grimace & 0 & $8 \quad(44.4 \%)$ & $<0.001$ \\
\hline $\begin{array}{l}\text { Overall unintelligillity: } \\
\text { Normal } \\
\text { Slight } \\
\text { Mild } \\
\text { Moderate } \\
\text { Severe }\end{array}$ & $\begin{array}{ll}44 & (84.6 \%) \\
8 & (15.4 \%) \\
0 & \\
0 & \\
0 & \end{array}$ & $\begin{array}{l}0 \\
8(44.4 \%) \\
4(22.2 \%) \\
2(11.1 \%) \\
4(22.2 \%)\end{array}$ & $<0.001$ \\
\hline
\end{tabular}


Table (3) shows $80 \%$ of those patients without VPI had average IQ but in case of those patients with VPI; 6 (33.3\%) patient had average IQ and $12(66.6 \%)$ patient had below average IQ according to Stanford-Binet Intelligence scale IV [5].

Table (3): IQ.

\begin{tabular}{llll}
\hline & $\begin{array}{c}\text { Without VPI } \\
(\mathrm{n}=52)\end{array}$ & $\begin{array}{c}\text { With VPI } \\
(\mathrm{n}=18)\end{array}$ & $\begin{array}{c}p \text { - } \\
\text { value }\end{array}$ \\
\hline$I Q:$ & & & \\
$\quad$ Unknown & $4(7.7 \%)$ & 0 & $<0.001$ \\
Average & $42(80 \%)$ & $6(33.3 \%)$ & \\
Below average & $6(11.5 \%)$ & $12(66.6 \%)$ & \\
\hline
\end{tabular}

\section{DISCUSSION}

Velopharyngeal dysfunction results from inadequate function of dynamic structures that work to control the velopharyngeal sphincter formed by the soft palate, the lateral pharyngeal walls, and the posterior pharyngeal wall), which separates the nasal cavity from the oral cavity during speech [7].

Dysfunction of this system may result in hypernasality, nasal air emission, decreased intraoral air pressure for oral pressure consonants, reduced speech loudness, nostril or facial grimacing [8].

There are strong relationships between IQ and language outcomes and between language skills and speech perception ability [9] which agrees with our study as $66 \%$ of patient with velopharyngeal dysfunction has below average IQ.

Conrad et al., found that adult with non-syndromic clefts of the lip and/or palate have a specific pattern of cognitive deficits. Subjects with cleft were found to have general IQ scores within the normal range, but significantly below that of their matched controls which agrees with our study [10].

Broen et al., [11] recognized the presence of difference between cleft patient and others on two developmental-cognitive measures administered when the children were 24 and 30 months old and on rate of vocabulary acquisition during their second year. Which is a key observation which affect the other IQ or speech development on cleft patient.

In our study we proved that is direct relation between cognitive ability of patient and incidence of occurrence of velopharyngeal dysfunction. The later affects the development of normal speech.

\section{Conclusion and Recommendations:}

At the end of our study we concluded the importance of multidisciplinary team on management of cleft palate patients specially speech pathologist as regarding our study we found $34 \%$ of our cases needed speech management.

We proved the direct relation between the age of palatoplasty, IQ (cognitive ability) and the occurrence of velopharyngeal dysfunction.

\section{Recommendation:}

The importance of applying the systemic speech examination on repaired cleft palate patient.

Further comprehensive study to recognize IQ effect on speech development on cleft palate patient.

\section{REFERENCES}

1- Luyten A., Bettens K., D'haeseleer E., Hodges A., Galiwango G., Vermeersch H., et al.: Short-term effect of short, intensive speech therapy on articulation and resonance in Ugandan patients with cleft (lip and) palate. Journal of Communication Disorders, 61: 71, 2016.

2- Nyberg J., Peterson P. and Lohmander A.: Speech outcomes at age 5 and 10 years in unilateral cleft lip and palate after one-stage palatal repair with minimal incision technique-a longitudinal perspective. International Journal of Pediatric Otorhinolaryngology, 78 (10): 1662, 2014.

3- Abdel-Aziz M.: Speech outcome after early repair of cleft soft palate using Furlow technique. International Journal of Pediatric Otorhinolaryngology, 77 (1): 85, 2013.

4- Nopoulos P., Berg S., VanDemark D., Richman L., Canady J. and Andreasen N.: Cognitive dysfunction in adult males with non-syndromic clefts of the lip and/or palate. Neuropsychologia, 40 (12): 2178, 2002.

5- Mayes S. and Calhoun S.: Analysis of WISC-III, StanfordBinet: IV, and academic achievement test scores in children with autism. Journal of Autism and Developmental Disorders, 33 (3): 329, 2003.

6- Kotby N., Haleem E.K.A., Hegazi M., Safe I. and Zaki M.: Aspects of assessment and management of velopharyngeal dysfunction in developing countries. Folia phoniatrica et logopaedica, 49 (3-4): 139-46, 1997.

7- Naran S., Ford M. and Losee J.: What's New in Cleft Palate and Velopharyngeal Dysfunction Management? Plastic and reconstructive surgery, 139 (6): 1343e, 2017.

8- Bettens K., Wuyts F. and Van Lierde K.: Instrumental assessment of velopharyngeal function and resonance: A review. Journal of Communication Disorders, 52: 170, 2014.

9- Sarant J., Hughes K. and Blamey P.: The effect of IQ on spoken language and speech perception development in children with impaired hearing. Cochlear implants international, 11: 370, 2010.

10- Conrad A., Richman L., Nopoulos P. and Dailey S.: Neuropsychological functioning in children with nonsyndromic cleft of the lip and/or palate. Child neuropsychology: A Journal on Normal and Abnormal Development in Childhood and Adolescence, 15 (5): 471, 2009.

11- Broen P., Devers M., Doyle S., Prouty J. and Moller K.: Acquisition of linguistic and cognitive skills by children with cleft palate. Journal of Speech, Language, and Hearing Research: JSLHR, 41 (3): 676, 1998. 